\title{
Variation in the number of activated torso receptors correlates with
}

\section{differential gene expression}

\author{
Marc Furriols ${ }^{1}$, Frank Sprenger ${ }^{2}$ and Jordi Casanova ${ }^{1}$ \\ ${ }^{1}$ Centre d'Investigació i Desenvolupament (CSIC) C/ Jordi Girona 18-26, 08034 Barcelona, Spain \\ 2Department of Biochemistry and Biophysics, University of California, San Francisco, California 94143-0448, USA
}

\section{SUMMARY}

Activation of receptor tyrosine kinases triggers many developmental decisions, yet we do not understand how activation of a single receptor can be transduced into different cell responses. The torso pathway in Drosophila provides a model to address this issue since it generates more than one response in the embryo. The torso receptor tyrosine kinase is activated at the embryonic poles under the control of trunk, a protein with similarities to several types of extracellular growth factors. Activation of torso is responsible for the development of a variety of structures, whose appearance can be correlated with activation of at least two different genes along the terminal region. In this study we have analyzed mutations in torso and trunk that express low levels of the respective proteins. We show that different amounts of torso or trunk molecules correlate with the expression of different zygotic genes, implicating changes in the number of activated torso molecules as one of the mechanisms defining differential gene expression. We suggest that variation in the number of activated receptors at the cell surface is a general mechanism that leads to differential gene expression and thus the generation of different cell responses.

Key words: torso, trunk, signal transduction, gene expresion, Drosophila, receptor tyrosinase kinase

\section{INTRODUCTION}

Receptor tyrosine kinases are involved in many developmental processes where they can elicit a variety of responses. A basic question in trying to understand their role in development is how activation of a single receptor can be transduced into different cell responses in terms of gene activation (for a review, see Marshall, 1995). The torso pathway in Drosophila is a particularly appropriate model with which to address this issue owing to its ability to generate more than one response in the embryo. The torso receptor tyrosine kinase is distributed along all the surface of the Drosophila embryo but is only activated at the poles, where it specifies development of its terminal structures (Schüpbach and Wieschaus, 1986; Klinger et al., 1988; Casanova and Struhl, 1989; Sprenger et al., 1989). Activation of the tor receptor has been shown to depend on a diffusible extracellular ligand generated at each pole that is trapped by the receptor, thereby impeding further diffusion (Sprenger and Nüsslein-Volhard, 1992; Casanova and Struhl, 1993). Recently, we have cloned trunk (trk), one of the genes required for tor activation, and have shown that it codes for a protein with similarities to several types of extracellular growth factors, which is likely to be the torso ligand (Casanova et al., 1995).

Activation of the torso signal transduction pathway is responsible for the activation of tailless ( $t l l)$ and huckebein $(h k b)$ at the posterior end of the embryo (Weigel et al., 1990). However, while tll is expressed in all this region, $h k b$ expression is activated only in its most terminal part (Pignoni et al., 1990; Brönner and Jäckle, 1991). One mechanism allowing differential gene expression could be an instructive torso activity gradient. Using mutations in torso in which activation is ligand-independent it has been possible to correlate distinct levels of tor signaling with differential gene activation (Casanova and Struhl, 1989): low levels of the constitutive torso activity are able to activate $t l l$ gene expression whereas only high levels can activate $h k b$ expression. However, it remains an open question whether such a mechanism is also used during normal development when wild-type torso is only activated at the poles. Alternatively, a gradient of tor receptor activity may not be responsible for organizing the terminal pattern. Instead, a sharp step function of active tor receptor at the cell surface could generate one or more gradients of activated intracellular substrates that could diffuse within the cytoplasm and specify the distinct elements of the terminal pattern (Casanova and Struhl, 1989).

Extra copies of either the tor gene or the trk gene do not alter the embryonic pattern, as judged by monitoring the expression of zygotic genes (Casanova and Struhl, 1989; our own unpublished observations), indicating that in those conditions they are not limiting factors. The molecular analysis of trk is consistent with this observation since it suggests that the trk protein, as many growth factors, needs to be processed to be active (Casanova et al., 1995). Overexpression of unprocessed trk could lead to minor changes in the amount of active trk only relevant in situations or domains where the tor receptor is a limiting factor. 
To investigate whether variations in the number of activated tor receptors at the cell surface might be responsible for distinct gene activation, we have generated situations in which the number of receptors or ligand molecules could be limiting. In particular, we have identified mutations that would give rise to low levels of either wild-type trk molecules secreted by the embryo or wild-type tor receptors at the cell surface, and have characterized their phenotypes. We used these mutations to demonstrate that different amounts of torso or trunk molecules correlate with expression of different zygotic genes, implicating changes in the number of activated torso molecules as one of the mechanisms defining differential gene expression.

\section{MATERIALS AND METHODS}

\section{Stocks}

$t r k^{1}, t r k^{4}, t r k^{5}$ and $t o r^{\mathrm{HM}}$ are EMS mutations induced by Trudi Schüpbach (Lindsley and Zimm). trk $^{1}$ results from a premature stop codon and behaves as a null allele (Casanova et al., 1995). tor $^{\mathrm{XR} 1}$ is a small deficiency that deletes the tor gene (Sprenger et al., 1989). $\mathrm{Df}(2 \mathrm{~L}) \mathrm{J} 77$ is a deficiency spanning from $31 \mathrm{C}$ to $31 \mathrm{~F}$ (T. Schüpbach, personal communication) that uncovers the trk gene. TR-11 is a third chromosome carrying a $6 \mathrm{~kb}$ genomic fragment that fully rescues the loss-of-function mutations in the trk gene. Egg laying took place at $25^{\circ} \mathrm{C}$.

\section{RNA analysis}

Poly $(\mathrm{A})^{+}$RNA was obtained from embryos with the PolyATract System (Promega), run in a $1.2 \%$ agarose gel containing formaldehyde and transferred to Hybond N (Amersham). Hybridization was performed with a trk-specific riboprobe derived from the antisense strand of the pR3 trk cDNA at $60^{\circ} \mathrm{C}$ in $50 \%$ formamide.

\section{Sequencing}

Genomic DNAs from $t r k^{4}, t r k^{5}$ and $t o r^{\mathrm{HM}}$ alleles, as well as genomic DNA from the isogenic stocks in which the mutations were induced, were PCR-amplified and sequenced. Two independent PCR products were sequenced in all the coding regions for each mutant strain and compared to the parental wild-type DNA in which the mutations were induced. For $t r k^{4}$, the only change that resulted in an amino acid substitution affected the codon for amino acid 18, which was changed from GGG (glycine) to AGG (arginine). No change was observed between the $t r k^{5}$ DNA and the parental wild-type DNA. In the $t o r^{\mathrm{HM}}$ allele, the only mutation that resulted in an amino acid change affected the codon for amino acid 11, which was changed from ATC (isoleucine) to AAC (asparagine).

\section{Plasmid constructions}

pBtor

pBtor has been described by Sprenger and Nüsslein-Volhard (1992).

\section{$\mathrm{pBHM}$}

The mutation detected in the $\operatorname{tor}^{\mathrm{HM}}$ allele was introduced into the pBtor cDNA by PCR. Using the oligos FS41 TTCCATGGTTATTTTCTATGCGAAGTACGCATTTAACTT and FS2 CCAATTGCATTTTGCTCCTGCC and pBtor as a template, a 1750 bp fragment was amplified, cut with $N c o$ I and BstXI, and the resulting $528 \mathrm{bp}$ fragment exchanged with the corresponding fragment of pBtor, yielding pBHM. In this vector the PCR-derived fragment was sequenced to exclude PCR-induced base changes.

\section{TR11}

A BamHI-EcoRI genomic fragment of around $6 \mathrm{~kb}$ from the trk region was inserted into the $\mathrm{P}\left(\mathrm{ry}^{+}\right)$transformation vector $\mathrm{C} 20$. This genomic fragment fully rescues the phenotype associated with the trk mutations.

\section{In situ hybridization}

$t l l$ and $h k b$ probes were generated from cDNA clones provided by $\mathrm{J}$. Lengyel and H. Jäckle, respectively. Whole-mount in situ hybridizations were done following the method of Tautz and Pfeifle (1989) with minor modifications.

\section{Western analysis}

Protein extracts were separated by SDS-PAGE, transferred to Immobilon membrane, and probed with anti-torso antibodies as described (Sprenger and Nüsslein-Volhard, 1992). Each lane contains material from approximately 20 eggs.

\section{RESULTS}

\section{Different amounts of the trk product can trigger different embryonic responses}

$t r k^{5}$ is a hypomorphic mutant allele. Embryos from $t r k^{5}$ females display a gradation of phenotypes ranging from $t r k^{-}$ null phenotypes to almost wild-type phenotypes. It is worth noting that those embryos with partial terminal development always lack the most terminal structures, those that are thought to require higher levels of terminal signaling. We have sequenced the DNA of the trk coding region from this mutant and have not found any change when compared to the wild-

Table 1. Dose-dependance of $\operatorname{trk}^{5}$ and tor ${ }^{\mathrm{HM}}$ phenotypes

\begin{tabular}{lcccc}
\hline & \multicolumn{2}{c}{ Size of terminal structure $(\%$ of embryos) } & \\
\cline { 2 - 4 } Maternal genotype & A7 segment & A8 segment & More terminal & n \\
\hline 1 copy of trk $^{5}$ & 22 & 76 & 1 & 143 \\
2 copies of trk $^{5}$ & 12 & 37 & 51 & 65 \\
1 copy of tor $^{\mathrm{HM}}$ & 76 & 24 & 0 & 41 \\
2 copies of tor $^{\mathrm{HM}}$ & 46 & 41 & 14 & 37
\end{tabular}

tor ${ }^{\mathrm{HM}}$ phenotypes are dependent on the dose of trk

\begin{tabular}{|c|c|c|c|c|c|}
\hline \multirow{2}{*}{\multicolumn{2}{|c|}{ Maternal genotype }} & \multicolumn{3}{|c|}{$\begin{array}{c}\text { Percentage of embryos } \\
\text { whose most posterior structures belong to }\end{array}$} & \\
\hline & & \multirow[t]{2}{*}{ A7 segment } & \multirow[t]{2}{*}{ A8 segment } & \multirow[t]{2}{*}{ More terminal } & \\
\hline $\begin{array}{l}\text { Copies of } \\
\text { tor } H M\end{array}$ & $\begin{array}{l}\text { Copies of } \\
\text { trk }^{+}\end{array}$ & & & & \\
\hline 1 & 1 & 98 & 2 & 0 & 48 \\
\hline 1 & 2 & 76 & 24 & 0 & 41 \\
\hline 1 & 3 & 61 & 39 & 0 & 41 \\
\hline 2 & 1 & 42 & 53 & 6 & 36 \\
\hline 2 & 2 & 46 & 41 & 14 & 37 \\
\hline 2 & 3 & 9 & 14 & 77 & 37 \\
\hline
\end{tabular}

Cuticles from embryos derived from females of the appropriate phenotypes were examined and classified according to whether their more terminal structures belonged to the seventh abdominal segment (A7), to the eight abdominal segment (A8), or were of more terminal origin such as the anal pads and tuft. n, number of embryos analysed for every genotype. Egg laying took place at $25^{\circ} \mathrm{C}$.

The actual genotypes for each combination are as follows:

1 copy of $t r k^{5}: t r k^{5} / \mathrm{Df}$ Jder 77 (similar results were obtained for $t r k^{5} / t r k^{1}$ ).

2 copies of $t r k^{5}: t^{5} k^{5}$ homozygous.

1 copy of $t o r^{\mathrm{HM}}$ and 1 copy of $t r k^{+}: t^{1} k^{1}$ tor $^{\mathrm{HM}} /$ tor $^{\mathrm{XR} 1}$

1 copy of $t o r^{\mathrm{HM}}$ and 2 copies of $t r k^{+}: t^{1} k^{1}$ tor ${ }^{\mathrm{HM}}$; TR11.

1 copy of $t o r^{\mathrm{HM}}$ and 3 copies of $t r k^{+}:$tor $^{\mathrm{HM}} /$ tor $^{\mathrm{XR} 1}$; TR11.

2 copies of $t o r^{\mathrm{HM}}$ and 1 copy of $t r k^{+}: t^{1} k^{1} t^{\mathrm{HM}}$; TR 11 .

2 copies of $t o r^{\mathrm{HM}}$ and 2 copies of $t k^{+}: t^{1} k^{1}$ tor $^{\mathrm{HM}} /$ tor $^{\mathrm{HM}}$; TR11.

2 copies of $t o r^{\mathrm{HM}}$ and 3 copies of $t r k^{+}: t^{\mathrm{HM}}$; TR11. 


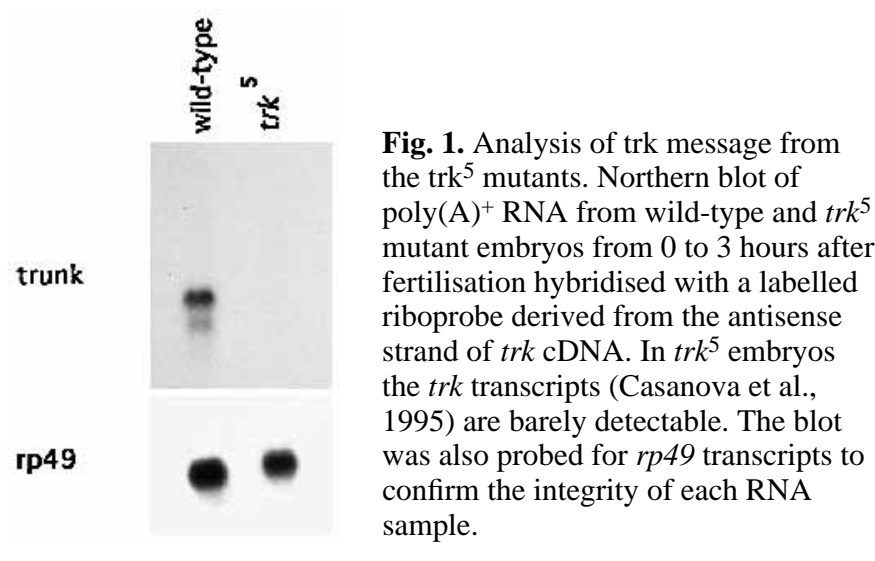

type gene. However, a northern blot reveals that the trk message is hardly detectable in embryos from $t r k^{5}$ females (Fig. 1), which suggests that a reduced amount of otherwise wild-type product is causing the mutant phenotype associated with the $t r k^{5}$ allele. Interestingly, the range of terminal deletions is dependent on the number of copies of the $t r k^{5}$ allele: embryos from females carrying two copies of the $t r k^{5}$ allele tend to have more terminal structures than those from females with just one copy of the $t k^{5}$ allele (Table 1; see table legend for exact phenotypes). Hence, we can correlate the amount of trk product with the appearance of different terminal structures and therefore with the level of tor signaling. Similar results were obtained with $t r k^{4}$, another hypomorphic mutant allele with a single amino acid substitution of a glycine for arginine at position 18 in the putative signal sequence (data not shown).

To extend this correlation to differential gene activation we have examined the activity of $t l l$ and $h k b$ in those embryos by in situ hybridization. As mentioned before, tor signaling is solely responsible for activating the expression of the genes $t l l$ and $h k b$ at the posterior end of the embryo (Weigel et al., 1990). Accordingly neither tll nor $h k b$ expression is detected at the posterior pole of $\mathrm{rrk}^{-}$ embryos (Fig. 2C,D), as it occurs in tor $^{-}$embryos (Brönner and Jäckle, 1991). We have examined independently $h k b$ and $t l l$ expression in embryos from $t r k^{5} / t r k^{-}$and $t r k^{5}$ homozygous females. Embryos from mothers of the same mutant genotype (either $\operatorname{trk}^{5} / t_{r k}$ or $t r k^{5}$ homozygous) exhibit some variability in their pattern of $t l l$ and $h k b$ expression, in agreement with the variability observed in the cuticle structures that they develop (see Table 1). However, while tll and $h k b$ expression is detected in some embryos from $t r k^{5}$ homozygous females (Fig. 2G,H), only tll expression but not $h k b$ expression is detected in some embryos from $t r k^{5} / t r k^{-}$females (Fig. 2E,F). It is worth noting that the domain of $t l l$ expression is often reduced in those embryos, suggesting that fewer tor receptors have been activated by the ligand diffusing from the poles. Thus, the amount of trk product from one copy of $t r k^{5}$ can trigger tor signaling to the levels required to activate $t l l$ but not $h k b$. Conversely, the amount of trk product from two copies of $t r k^{5}$ can trigger tor signaling to the levels required to activate both $t l l$ and $h k b$.

\section{Different numbers of tor receptors activated at the cell surface can originate diverse terminal structures}

$t^{\mathrm{HM}}$ is a temperature-sensitive allele in which no terminal structures are present when embryos are raised at high temperatures $\left(27^{\circ} \mathrm{C}\right)$. At $18^{\circ} \mathrm{C}$, on the other hand, terminal structures are present (Sprenger, 1991). tor $^{\mathrm{HM}}$ encodes a protein with a single amino acid substitution of an asparagine for isoleucine at position 11 in the signal sequence. This change results in a significant alteration of the hydrophobicity of the leader peptide. In western blots the majority of tor ${ }^{\mathrm{HM}}$ migrates differently from the mature wild-type protein that is glycosylated (F. S., unpublished data) and with an electrophoretic mobility that compares to the non-glycosylated form (Fig. 3) (for details see legend to Fig. 3). When embryos are developed at lower temperatures, in which terminal structures are present, small amounts of tor ${ }^{\mathrm{HM}}$ protein can be
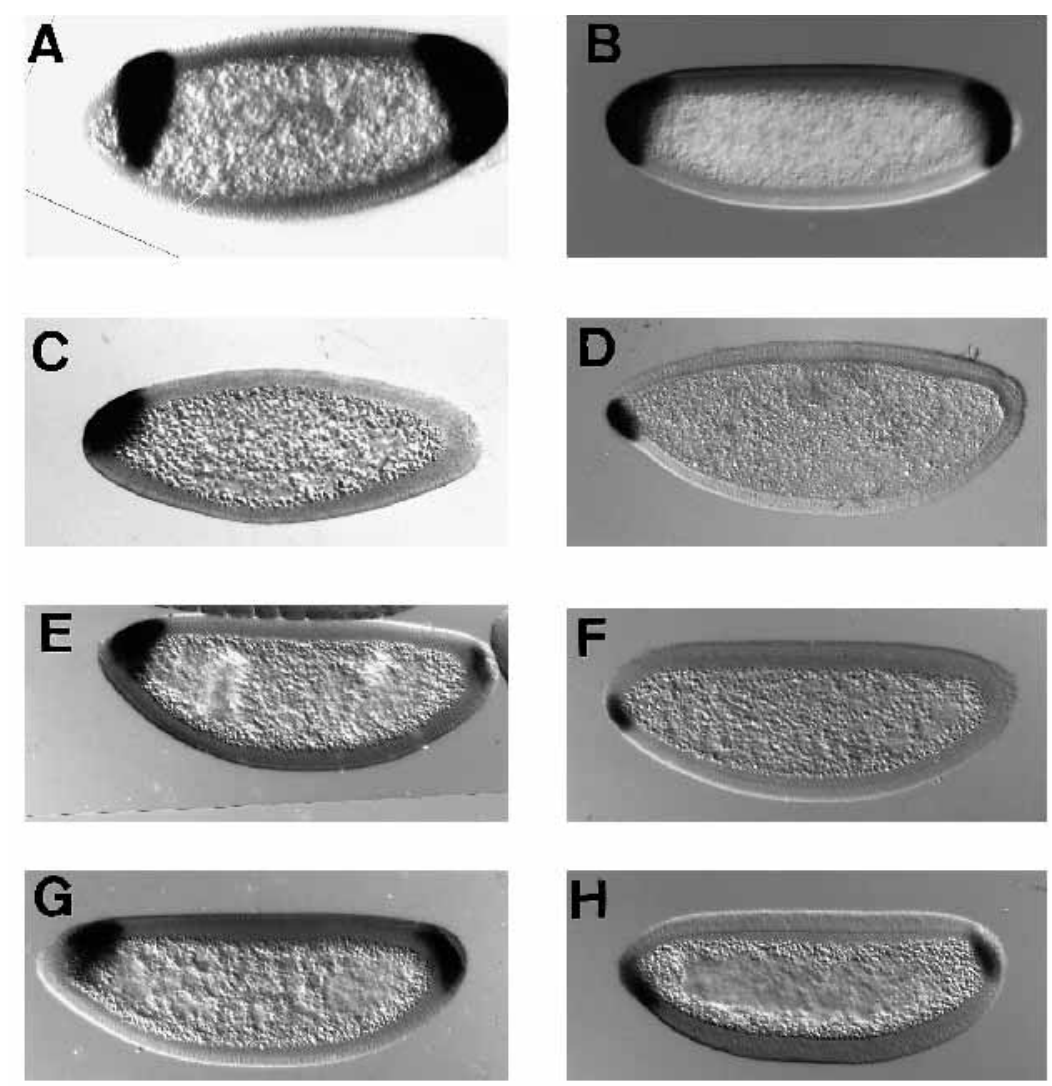

Fig. 2. $t l l$ and $h k b$ expression in trk mutant embryos. $t l l$ (A,C,E,G) and $h k b$ $(\mathrm{B}, \mathrm{D}, \mathrm{F}, \mathrm{H})$ expression, as monitored by in situ hybridisation. $(\mathrm{A}, \mathrm{B})$ At the blastoderm stage, $t l l$ and $h k b$ are expressed at both poles of the embryo. (C,D) In embryos from trk ${ }^{1}$ mothers, neither $t l l$ nor $h k b$ expression is detected in the posterior pole; expression remains in the anterior domain, since at the anterior end the terminal signal acts in conjunction with the anterior system.

(E,F) Embryos from females with one copy of the $t r k^{5}$ allele $\left(t r k^{5} / t r k^{1}\right)$. tll expression is detected in some of those embryos; however, $h k b$ expression is not detected. $(\mathrm{G}, \mathrm{H})$ Embryos from females with two copies of the $t^{5} k^{5}$ allele $\left(t r k^{5}\right.$ homozygous); both $t l l$ and $h k b$ expression can be detected among those embryos. 


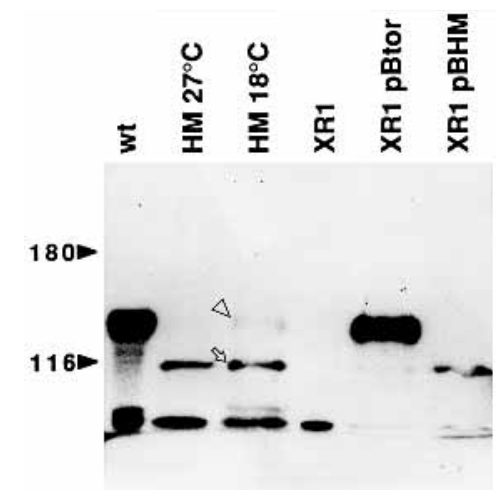

Fig. 3. Torso expression in $t o r^{\mathrm{HM}}$ mutant eggs. wt, 0-3 hour wildtype eggs $\left(22^{\circ} \mathrm{C}\right)$. HM $27^{\circ} \mathrm{C}, 0-3$ hour eggs from tor $^{\mathrm{HM}}$ homozygous mothers developed at $27^{\circ} \mathrm{C}$. HM $18^{\circ} \mathrm{C}, 0-4$ hour eggs from tor ${ }^{\mathrm{HM}}$ homozygous mothers developed at $18^{\circ} \mathrm{C}$. XR1, 0-3 hour eggs $\left(22^{\circ} \mathrm{C}\right)$ from tor ${ }^{\mathrm{XR} 1}$ homozygous mothers that lack torso protein. XR1 pBtor, 0-1 hour eggs from tor ${ }^{\mathrm{XR} 1}$ homozygous mothers were injected with 1 $\mathrm{mg} / \mathrm{ml} \mathrm{pBtor} \mathrm{mRNA}$, encoding wild-type torso protein, and incubated for 2 hours at $22^{\circ} \mathrm{C}$. XR1 pBHM, 0-1 hour eggs from tor $^{\mathrm{XR} 1}$ homozygous mothers were injected with $1 \mathrm{mg} / \mathrm{ml} \mathrm{pBHM}$ mRNA, encoding the tor ${ }^{\mathrm{HM}}$ protein, and incubated for 2 hours at $22^{\circ} \mathrm{C}$. Most of the torso protein of embryos from tor ${ }^{\mathrm{HM}}$ homozygous mothers migrates with faster electrophoretic mobility than wild-type torso. The approximate size of this tor ${ }^{\mathrm{HM}}$ protein (arrow) compares to the non-gylcosylated form of torso. However, at $18^{\circ} \mathrm{C}$, a little bit of wild-type sized torso can be detected (arrowhead). To show that the change found in the sequence of tor ${ }^{\mathrm{HM}}$ is solely responsible for the tor $^{\mathrm{HM}}$ phenotype, the mutation was introduced into the $\mathrm{pBtor}$ cDNA, the resulting cDNA (pBHM) transcribed in vitro and the RNA injected into embryos that lack endogenous torso. In these embryos, the tor ${ }^{\mathrm{HM}}$ produced from the injected RNA migrated with the same electrophoretic mobility as torso from embryos mutant for tor $^{\mathrm{HM}}$. In addition, only a little induction of terminal structures was observed, similar to tor $^{\mathrm{HM}}$ mutant embryos developed at $22^{\circ} \mathrm{C}$ (not shown).

detected that migrate with the same electrophoretic mobility as wild-type torso. However, the majority of the tor ${ }^{\mathrm{HM}}$ protein still migrates like non-glycosylated wild-type torso molecules. This suggests that the first amino acids of the tor ${ }^{\mathrm{HM}}$ molecule are a very poor leader peptide. The majority of protein does therefore not get glycosylated and does not get incorporated into the cytoplasmic membrane. Only at lower temperatures is a small fraction of tor ${ }^{\mathrm{HM}}$ apparently glycosylated and presumably reaches the cytoplasmic membrane.

The $t o r^{\mathrm{HM}}$ mutant phenotype, similar to the $t r k^{5}$ mutation, is dose-sensitive (Table 1). Interestingly, the $t o r^{\mathrm{HM}}$ phenotype is very sensitive to the dose of the trk gene. We have analyzed the phenotype of embryos from females at $25^{\circ} \mathrm{C}$ carrying either one or two copies of the $t o r^{\mathrm{HM}}$ gene and varying doses of the trk gene (Table 1). For a given number of tor receptors, an increase in the doses of trk results in the appearance of more terminal structures, indicating that a higher level of terminal signaling is being generated. Under these experimental conditions, the sole variation lies in the number of tor or trk molecules, implying that it is the different number of activated tor receptors that dictates the expression of the distinct genes responsible for the determination of diverse terminal structures.

\section{DISCUSSION}

\section{The torso signal transduction and generation of pattern}

Activation of the torso pathway is responsible for specifying the terminal portions of the embryo, which include a variety of structures that appear in an organized pattern. The generation of this pattern involves the activation of at least two different genes along the terminal region. An open question is how activation of the torso receptor can lead to differential gene expression. By using mutations coding for constitutive torso receptors it has been possible to show that the level of active tor protein can be causally related to the specification of particular portions of the terminal pattern (Casanova and Struhl, 1989). However, it has been pointed out that these results should be interpreted with caution, as mutant proteins with altered activity may represent unique situations that a wild-type form of the tor protein may not be capable of achieving (Duffy and Perrimon, 1994). Here we report the identification of mutations that either reduce the amount of trk molecules or that lower the amount of tor receptors at the cell surface. These mutations allow us to show that variation in the number of activated torso receptors can be correlated with differential expression of the distinct genes responsible for the determination of diverse terminal structures. Probably other factors are also involved in translating the tor signal into the proper pattern. For instance, diffusion of intracellular phosphorylated substrates could also generate an instructive gradient specifying different pattern elements. Moreover, many experiments suggest that uniform levels of ubiquitous tor activity (Casanova and Struhl, 1989) or uniform levels of signal transducers (Casanova et al., 1994) can generate organized pattern. These observations suggest that the terminal signal can also be modulated by its interaction with other molecules present in the embryo (e.g. gap gene products) to give rise to differential gene expression. In wild-type development all these mechanisms might cooperate to translate the terminal signal into distinct domains of gene expression responsible for organization of the terminal pattern.

\section{Variation in the number of activated receptors at the cell surface: a general mechanism to elicit distinct responses from cells?}

In this report, we have shown that by modulating the amount of receptor and activating molecules we can elicit different responses in cells, in terms of their gene activation. Recently, results have been reported showing that stimulation of overexpressed EGF receptor can mimic the cellular response to activation of the NGF receptor (Traverse et al., 1994). Conversely, reduction in the amount of the NGF receptor can mimic the cellular response to EGF receptor activation (Schlessinger and Bar-Sagi, 1995). This behavior has been interpreted as a quantitative difference in ERK activation that is translated into a qualitative difference in transcription factor activation, but a limitation of this model is that it is based wholly on 'in vitro' experiments with PC12 cells (Marshall, 1995). In addition, many other transducing signaling pathways operating in development have been shown to generate graded responses. This is the case for the dorsoventral patterning in Drosophila (Roth et al., 1989; Rushlow et al., 1989; Steward, 1989; Chasan and Anderson, 1993), embryonic ventral 
ectoderm determination also in Drosophila (Schweitzer et al., 1995) and for patterning of vulval fates in Caenorhabditis elegans (Sternberg and Horvitz, 1986; Hill and Sternberg, 1993). Here we document the case of the terminal system where activation of a unique transduction pathway can elicit at least two responses in terms of gene activation and we show this by altering the number of activated receptors at the cell surface. We would like to suggest that variation in the number of activated receptors, by changes either in ligand concentration or in the amount of receptor present at the cell surface, could represent a general mechanism to elicit distinct responses from cells.

We thank H. Doyle for the initial identification of the tor $^{\mathrm{HM}}$ phenotype and T. Schüpbach, J. Lengyel and H. Jäckle for providing flies and materials. We also thank A. González-Reyes, G. Struhl R. Wharton and L. Ambrosio for comments on the manuscript, our colleagues in the laboratory for many discussions and Nicolás Martín for his technical assistance. M.F. is supported by a fellowship from the Minsterio de Educacion y Ciencia and Marató de TV3. This work was supported by the DGICYT, CIRIT and the Fundación Ramón Areces.

\section{REFERENCES}

Brönner, G. and Jäckle, H. (1991). Control and function of terminal gap gene activity in the posterior pole region of the Drosophila embryo. Mech. Dev. 35, 205-211.

Casanova, J. and Struhl, G. (1989). Localized surface activity of torso, a receptor tyrosine kinase, specifies terminal body pattern in Drosophila. Genes Dev. 3, 2025-2038.

Casanova, J. and Struhl, G. (1993). The torso receptor localizes as well as transduces the spatial signal specifying terminal body pattern in Drosophila. Nature 362, 152-155.

Casanova, J., Llimargas, M., Greenwood, S. and Struhl, G. (1994). An oncogenic form of human raf can specify terminal body pattern in Drosophila. Mech. Dev. 48, 59-64.

Casanova, J., Furriols, M., McCormick, C. A. and Struhl, G. (1995). Similarities between trunk and spätzle, putative extracellular ligands specifying body pattern in Drosophila. Genes Dev. 9, 2539-2544.

Chasan, R. and Anderson, K. V. (1993). Maternal control of dorsal-ventral polarity and pattern in the embryo. In The Development of Drosophila melanogaster (ed. M. Bate and A. Martínez-Arias), pp. 387-424. Cold Spring Harbor Laboratory Press: Cold Spring Harbor, NY.

Duffy, J. B. and Perrimon, N. (1994). The torso pathway in Drosophila: lessons on receptor tyrosine kinase signaling and pattern formation. Dev. Biol. 166, 380-395.

Hill, R. J. and Sternberg, P. W. (1993). Cell fate patterning during C. elegans vulval development. In Signals, Polarity and Adhesion in Development (ed.
P. Ingham, A. Brown and A. Martínez-Arias), pp. 9-18. The Company of Biologists Limited: Cambridge, UK.

Klingler, M., Erdelyi, M., Szabad, J. and Nüsslein-Volhard, C. (1988). Function of torso in determining the terminal anlagen of the Drosophila embryo. Nature 335, 275-277.

Marshall, C. J. (1995). Specificity of receptor tyrosine kinase signaling: transient versus sustained extracellular signal-regulated kinase activation. Cell 80, 179-185.

Pignoni, F., Baldarelli, R. M., Steingrímsson, E., Diaz, R. J., Patapoutian, A., Merriam, J. R. and Lengyel, J. A. (1990). The Drosophila gene tailless is expressed at the embryonic termini and is a member of the steroid receptor superfamily. Cell 62, 151-163.

Roth, S., Stein, D. and Nüsslein-Volhard, C. (1989). A gradient of nuclear localization of the dorsal protein determines dorsoventral pattern in the Drosophila embryo. Cell 59, 1189-1202.

Rushlow, C. A., Han, K., Manley, J. L. and Levine, M. (1989). The graded distribution of the dorsal morphogen is initiated by selective nuclear transport in Drosophila. Cell 59, 1165-1177.

Schlessinger, J. and Bar-Sagi, D. (1995). Activation of ras and other signaling pathways by tyrosine receptor kinases. In Symposia on Quantitative Biology: Molecular Genetics of Cancer, vol. 60. Cold Spring Harbor Laboratory Press: Cold Spring Harbor, NY. (As cited in Marshall, 1995.).

Schüpbach, T. and Wieschaus, E. (1986). Maternal-effect mutations altering the anterior-posterior pattern of the Drosophila embryo. Roux's Arch. Dev. Biol., 195, 302-317.

Schweitzer, R., Shaharabany, M., Seger, R. and Shilo, B.-Z. (1995). Secreted Spitz triggers the DER signaling pathway and is a limiting component in embryonic ventral ectoderm determination. Genes Dev 9 , 1518-1529.

Sprenger, F., Stevens, L. M. and Nüsslein-Volhard, C. (1989). TheDrosophila gene torso encodes a putative receptor tyrosine kinase. Nature 338, 478-483.

Sprenger, F. (1991). PhD Thesis. Molekulare Untersuchungen zur Funktion und Regulation des maternale Gens torso bei der Determinierung terminaler strukturen im Drosophila Embryo. Eberhard-Karls-Universitaet, Tuebingen.

Sprenger, F. and Nüsslein-Volhard, C. (1992). Torso receptor activity is regulated by a diffusible ligand produced at the extracellular terminal regions of the Drosophila egg. Cell 71,987-1001.

Sternberg, P. W. and Horvitz, H. R. (1986). Pattern formation during vulval development in Caenorhabditis elegans. Cell 44, 761-772.

Steward, R. (1989). Relocalization of the dorsal protein from the cytoplasm to the nucleus correlates with its function. Cell 59, 1179-1188.

Tautz, D. and Pfeifle, C. (1989). A non-radioactive in situ hybridization method for the localization of specific RNAs in Drosophila embryos reveals translational control of the segmentation gene hunchback. Chromosoma 98, 81-85.

Traverse, S., Seedorf, K., Paterson, H., Marshall, C. J., Cohen, P. and Ullrich, A. (1994). EGF triggers neuronal differentitation of PC12 cells that overexpress the EGF receptor. Curr. Biol. 4, 694-701.

Weigel, D., Jürgens, G., Klinger, M. and Jäckle, H. (1990). Two gap genes mediate maternal terminal pattern information in Drosophila. Science $\mathbf{2 4 8}$, 495-498. 